\title{
PERCURSOS DE FORMAÇÃO DE UMA ALUNA-PESQUISADORA
}

\author{
MORAIS, Jacqueline de Fátima dos Santos ${ }^{1}$ - FFP-UERJ \\ PORTUGAL, Naila de Figueiredo ${ }^{2}$ - FFP-UERJ
}

\section{RESUMO:}

Este texto busca refletir sobre o processo de compreender-se e assumir-se pesquisadora ao mesmo tempo que estudante da universidade. A partir da experiência vivida por uma das autoras, o artigo analisa diferentes atividades e espaços de formação: a monitoria, a iniciação científica, a participação em um grupo de pesquisa e a imersão em espaços culturais. As autoras concluem a importância da ampliação do conceito de formação docente, entendendo que a multiplicidade de tempos e locais formam o estudante-pesquisador.

PalAVRAS-CHAVE: Práticas docentes - Formação de professores - Alfabetização.

\begin{abstract}
:
This text aims to reflect about the process lived by a university student on the challenge of understanding herself as a researcher. From the experience lived by one of the authors, the article analyzes different activities and training spaces: monitoring, scientific initiation, participation in a research group and the immersion in cultural spaces. The authors conclude the importance of expanding the concept of teacher training, I understand that the multiplicity of times and locations form the student-researcher. The authors conclude the work with the defense of the importance of expanding the concept of teacher training, through the understanding that a student becomes a researcher by living experiences in many different places and times.
\end{abstract}

KEYWORDS: Teaching practices - Teacher training - Literacy.

\footnotetext{
${ }^{1}$ Doutora em Educação pela Unicamp. Professora adjunta na Faculdade de Formação de Professores da UERJ. E- mail: jacquelinemorais@hotmail.com

${ }^{2}$ Graduada em Pedagogia pela Universidade do Estado do Rio de Janeiro (UERJ). E- mail: nailaportugal@hotmail.com
} 


\section{INICIANDO O DEBATE}

Faz parte da natureza da prática docente a indagação, a busca, a pesquisa. O de que se precisa é que, em sua formação permanente, o professor se perceba e se assuma, porque professor, como pesquisador. (FREIRE, 1997, p. 32)

Este texto resulta da experiência vivida por Naila, aluna do curso de pedagogia da Faculdade de Formação de Professores de São Gonçalo, uma das autoras deste texto, durante o processo de compreenderse e assumir-se pesquisadora. Este processo culminou na produção de sua monografia final de curso, sob orientação de Jacqueline Morais e que, em parte, trazemos neste artigo. Desta forma, temos um texto que foi se fazendo em parceria, sendo discutido e ampliado num movimento de interação e interlocução. Um texto também vivido como espaço de formação. E é desta forma, em dupla autoria, que ele se apresenta.

A participação de uma estudante em uma pesquisa como bolsista, possibilita a construção de olhares outros para a educação. No caso de Naila, foram três movimentos que marcaram e constituíram sua trajetória como aluna-pesquisadora. Estes movimentos foram: o Grupo de Pesquisa coordenado por Jacqueline Moras; as ações de pesquisa e extensão que representam o Fórum de Alfabetização, Leitura e Escrita (FALE São Gonçalo) e o Grupo de Estudos e Pesquisa das/os Professoras/es Alfabetizadoras/es Narradoras/es (GEPPAN).

Em sua monografia, Naila analisa alguns dos diferentes espaços de formação nos quais transitou de maio de 2012 à fevereiro de 2013, buscando responder a questão: Que espaços e experiências contribuíram para minha assunção como alunapesquisadora? Em relação à metodologia de pesquisa, sua monografia, ao trazer alguns elementos do seu percurso pessoal e acadêmico, se aproxima de uma pesquisa de cunho autobiográfico. Neste sentido, o memorial se constitui como uma importante parte da monografia.

Dentre outros espaços, Naila discute a importância de sua experiência como bolsista de monitoria e Iniciação Científica. Analisa também a relevância de frequentar espaços culturais como teatro, cinema, museus e centros culturais para a ampliação do capital cultural. Debate o valor de participar de eventos acadêmicos como seminários e congressos. Reflete sobre a pesquisa focada no Fórum de Alfabetização, Leitura e Escrita de São Gonçalo, analisando a importância do diálogo entre universidade e escola básica e a construção de formas de superação das práticas alfabetizadoras tradicionais em direção à palavramundo de que nos fala Paulo Freire.

\section{MONITORIA: ESPAÇO DE FORMAÇÃO}

Um dos espaços de formação que uma estudante do curso de pedagogia pode ter, está na atividade de monitoria de uma disciplina. Esta é uma modalidade de bolsa oferecida pela UERJ e regulamentada pela deliberação no 047/95. Segundo este documento, a monitoria tem por objetivo:

Art. 10 - ...o aperfeiçoamento do processo de formação profissional pela melhoria da qualidade de ensino, criando condições para o aprofundamento teórico e o desenvolvimento de habilidades relacionadas à atividade docente.

Art. $2^{\circ}$ - Os objetivos da monitoria são: estimular no aluno o interesse 
pela atividade docente e oferecer oportunidade para desenvolvê-la, intensificando a relação entre 0 corpo docente e o discente, nas atividades de ensino. $(1995$, p. 1)

Se, por um lado, temos objetivos oficiais que regulamentam esta atividade, por outro, quando confrontamos com as conversas que temos com vários estudantes, percebemos que a atividade de monitoria, muitas vezes, tem se restringido a mera substituição do professor/a coordenador/a em sua ausência durante o tempo de aula. Assim, a monitoria acaba se tornando, na universidade, uma maneira de evitar a suspensão de aulas e os conflitos que esta situação causaria. A substituição de professores por monitores, nas atividades docentes, porém, como pudemos ver acima, não está prevista pela legislação que regulamenta esta atividade, sendo assim inadequada. Além de inapropriada, pensamos que este tipo de atuação do monitor não possibilita o alcance dos objetivos a que o artigo primeiro se refere, quando aponta que o aprofundamento teórico e o desenvolvimento das habilidades relacionadas à docência devem ser buscados nesta modalidade de bolsa. Desta forma, entendemos a importância das ideias de Freire (1997, p. 32), ao defender que: não há ensino sem pesquisa e pesquisa sem ensino. Por isso, a atividade do monitor deve estar vinculada ao ensino, mas também à pesquisa, já que o entrelaçamento destas duas dimensões, ensino e pesquisa, pode contribuir para o desenvolvimento da "curiosidade epistemológica" de que fala ainda Freire (1997, p.27).

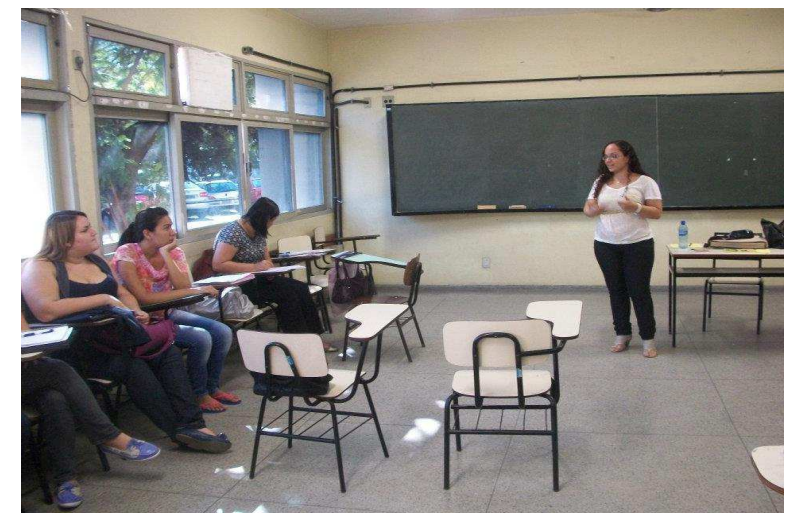

Figura 1: Naila em atividade de monitoria da disciplina Alfabetização III- Arquivo Pessoal

Naila iniciou sua experiência como monitora da disciplina "Alfabetização III", ministrada pela Profa Jacqueline Morais, em maio de 2012. As aulas ocorriam às segundas-feiras das $7 \mathrm{~h}$ às $10 \mathrm{~h}$ e $40 \mathrm{~min}$. Naila viveu a monitoria como espaço de ensino e aprendizagem, ajudando e sendo ajudada a ampliar conhecimentos sobre alfabetização, vivendo relações com a professora e com as alunas da disciplina, buscando compreender que não há ensino sem pesquisa e pesquisa sem ensino, no sentido dado por Freire, na referência exposta mais acima.

Pensamos ser interessante, para entendermos o percurso histórico e ao mesmo tempo os marcos legais desta modalidade de atuação que Naila pode viver na UERJ, levar em conta que a Lei de Diretrizes e Bases da Educação Nacional, publicada em 1996, preconizava, em seu artigo 84, que "os discentes da Educação Superior poderão ser aproveitados em tarefas de ensino e pesquisa pelas respectivas Instituições exercendo funções de monitoria, de acordo com seu rendimento e seu plano de estudos." Assim, podemos entender que a monitoria foi pensada como um projeto de atuação nas universidades brasileiras e não apenas na UERJ. Desta forma, encontramos monito- 
res de disciplina em todas as universidades públicas deste país.

Uma ação que destacamos da atuação de Naila como monitora da disciplina Alfabetização foi a realização de dinâmicas com a turma, sempre no início da aula. Levando em consideração o segundo artigo da deliberação $n^{\circ}$ 047/95, que aponta que um dos objetivos da monitoria é estimular o interesse pela atividade docente, despertado através de atividades que intensifiquem a relação entre o corpo docente e discente, pensamos que as dinâmicas propostas ao grupo de estudantes puderam criar um clima de interação com e entre as alunas, e entre elas e a professora. Neste processo, todas aprendemos já que, como Freire (1997) aponta: "toda prática educativa demanda existência de sujeitos, um que, ensinando, aprende, outro que, aprendendo, ensina." (p. 69)

Aprendemos muito através dos diálogos e reflexões provocadas pelas dinâmicas feitas em sala de aula. As interações vividas entre os sujeitos que compunham aquela sala de aula, favoreceram os movimentos que poderíamos chamar, inspiradas em Freire, de ensinante e aprendente (1997). Estes movimentos possibilitaram construções e desconstruções, aprendizagens, avanços, recuos, a cada atuação de Naila como monitora ou, como poderíamos chamar, a cada ação como "alunapesquisadora".

As dinâmicas eram realizadas no início de cada aula e produziam, em nós, novas reflexões sobre o processo aprendizagem-ensino-aprendizagem, não apenas aqueles ligados à alfabetização, mas também processos que ocorriam durante o curso de Pedagogia. Essas dinâmicas se estruturavam através do diálogo com as alunas. A necessária escuta sensíve/ de que nos fala Barbier (1997, p. 357), tornava-se cada vez mais aguçada à medida que o relacionamento com as alunas da disciplina Alfabetização ia se estreitando.

Jacqueline lia uma história ao iniciar cada aula. Uma das razões era despertar o interesse das alunas (e futuras professoras) pela leitura de histórias para seus (futuros) alunos dos anos iniciais. Penso que a ideia ali posta em prática era possibilitar que as estudantes do curso de pedagogia vivessem uma experiência estética com a literatura. Uma experiência que, sendo um atravessamento, representasse e produzisse um movimento formativo. Larrosa (2002) afirma que "A experiência é o que nos passa, o que nos acontece, o que nos toca." (p.21) Assim, a leitura de textos e livros de literatura infantil, e não somente de texto da chamada "literatura acadêmica", representou uma tentativa de que algo "acontecesse" com as alunas, de que algo lhes "tocasse", de que algo lhes "passasse". É claro que não há garantia de que este objetivo tenha sido alcançado com todas as alunas. No entanto, sendo a palavra experiência, como diz ainda Larrosa (p.25), oriunda do latim "experiri", que significa provar, experimentar, pensamos que ler literatura para as alunas faça parte de um compromisso e uma aposta. Possibilidade de que a literatura se torne uma experiência, um encontro, uma relação que se possa experimentar, que se possa provar. E, provando, quem sabe as alunas possam aprovar essa experiência? Morais (2002) afirma que: "É assim, contando e lendo histórias para crianças desde bem cedo, que vamos cumprindo a sina de todo professor e professora: apaixonar seus alunos e alunas para o mundo da narrativa, onde a literatura é uma das formas de seu registro escrito." (p.4)

O encantamento pela leitura pode ser despertado nos alunos através da leitura de uma boa narrativa. A cada história, novas possibilidades de leitura dos textos es- 
critos e da vida podem ser construídas pelas crianças, mas também pela professora que se deixa atravessar pela literatura.

Assim, parte da formação de Naila, aluna que vai se tornando pesquisadora, se construiu a partir das experiências que viveu como monitora da disciplina Alfabetização. Em relação à importância formativa desta atividade acadêmica, Frison e Moraes (2010) afirmam que: "O valor formativo desse trabalho está, sobretudo, no investimento feito por cada aluno no momento que autorregula sua aprendizagem, e, também, na promoção do auto-conceito e da auto-formação que a monitoria oferece." (p.157)

Consideramos significativo o potencial valor formativo que a monitoria oferece para os estudantes da graduação, tanto no que se refere ao percurso acadêmico, como no processo de crescimento pessoal. As experiências de monitoria podem ajudar os estudantes a pensarem na complexidade da atuação docente e nos desafios que poderão enfrentar como professores na escola básica.

\section{INICIAÇÃo Científica: OUTRO ESPAÇO DE FORMAÇÃO}

A UERJ, além de monitoria, oferece a possibilidade de bolsas nas modalidades: Estágio Interno Complementar, Iniciação Científica, Iniciação à Docência e Extensão.

Em outubro de 2012, Naila migrou da bolsa de monitoria para bolsa de Iniciação Científica. Esta nova experiência permitiu viver e compreender um pouco mais do que significava ser aluna-pesquisadora.

O Programa Institucional de Bolsas de Iniciação Científica (PIBIC) criado pelo CNPq em 1988 e instituído na UERJ em 1992, é um programa voltado para o desenvolvimento do pensamento científico e inici- ação à pesquisa de estudantes de graduação da UERJ, e visa à produção do conhecimento sob a orientação de professor pesquisador ${ }^{5}$. Um dos objetivos do Programa Institucional de Bolsas de Iniciação Científica (PIBIC) é:

\begin{abstract}
proporcionar ao bolsista, orientado por pesquisador qualificado, a aprendizagem de técnicas e métodos de pesquisa, bem como estimular o desenvolvimento do pensar cientificamente e da criatividade, decorrentes das condições criadas pelo confronto direto com os problemas de pesquisa.
\end{abstract}

O trabalho de pesquisa exigiu a leitura de autores como: Regina Leite Garcia, Nilda Alves, Jorge Larossa, Walter Benjamin, Daniel Suárez, dentre outros - autores ainda pouco lidos no curso de formação de professores. O movimento de estudo e pesquisa resultou na saída do lugar de acomodação para o lugar do movimento. Estes pesquisadores nos fazem sair da zona de conforto e ressignificar e reconstruir posicionamentos. Com eles, podemos compreender que a escola básica e universidade devem dialogar, já que ambos são espaços de construção de conhecimento legítimo.

Estes autores nos convidaram a compreender que as narrativas docentes são legítimas e devem ser compartilhadas com alunos da formação inicial e outros professores, pois através deste movimento, o de circulação de experiências, novos e outros saberes podem ser construídos. Aprendemos que, em um mundo acelerado de informações, as experiências tornaramse cada dia mais raras. Hoje as situações

5 Para maiores informações acessar o site http://www.pibic.sr2.uerj.br/index.php?option=c om_content\&view $=$ article\&id $=48 \&$ Itemid $=55$ 
simplesmente passam e raramente nos atravessam. Fomos convidadas a olhar a escola como lugar de potência e seu cotidiano, como espaço de importantes acontecimentos. Aprendemos que as formas mais tradicionais e, ainda hegemônicas, de ensino têm contribuído para a criação de sujeitos não críticos. Aprendemos que as crianças devem ser ouvidas e que elas possuem múltiplos conhecimentos e uma rica leitura de mundo. Estas foram algumas das aprendizagens que pudemos ter com os autores lidos.

Como bolsista de Iniciação Científica, Naila teve a oportunidade de apresentar o trabalho "Formação Continuada: Experiências e Narrativas Docentes" na $21^{\text {a }}$ Semana de Iniciação Científica da UERJ Sem Muros, realizada de $1^{\circ}$ a 5 de outubro de 2012. A UERJ Sem Muros é um evento que acontece na UERJ e mobiliza toda Universidade na apresentação da produção acadêmica realizada nas diversas áreas de conhecimento, envolvendo ensino, pesquisa, extensão e cultura ${ }^{6}$.

Em meio a 875 apresentações de trabalho, a apresentação de Naila recebeu o $1^{\circ}$ lugar no "Prêmio de Iniciação à Ciência: Professor Evanildo Bechara" em Ciências Humanas.

Esta experiência nos permite pensar como Souza (2011) que:

A participação em eventos científicos é uma oportunidades na qual o aluno de IC encontra seus pares, troca experiências e vivências, bem como se expõe ao público do evento. Apresentar o trabalho em congresso é colocar o estudante diante de sua comunidade científica, de

6 Para maiores informações, acessar o site http://www.sr3.uerj.br/usm/index-2.php uma audiência de pares com atitude crítica, científica e com genuíno interesse no avanço do trabalho. ( $\mathrm{p}$. 230)

Desta forma, ao apresentar-se em um evento, o bolsista tem a oportunidade de assistir a diversas exposições de trabaIhos, além de compartilhar saberes com outros alunos. Pode aprender sobre as diferentes perspectivas de pesquisa, sobre múltiplas possibilidades teóricas e metodológicas na produção da investigação no campo das Ciências Humanas. A participação de estudantes na pesquisa traz inúmeras consequências para a formação deste sujeito, apontando o quanto vale a pena investir no/a estudante pesquisador/a.

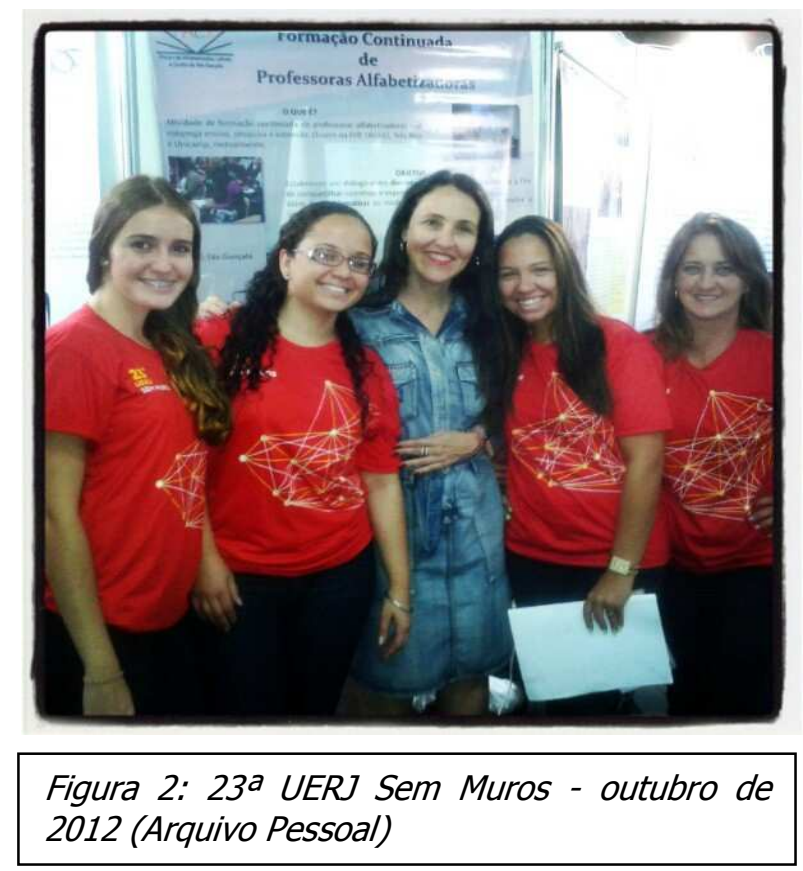
Grupo De Pesquisa: também espaço de
FORMAÇÃo 
O nosso grupo de pesquisa é vinculado ao grupo Vozes da Educação: Escola e Memória das Escolas de São Gonçalo. Ambos estão sediados na Faculdade de Formação de Professores da UERJ, localizada no Bairro Paraíso, na Rua Dr. Francisco Portela, 1470.

No início de 2013, nosso grupo de pesquisa totalizava um número de 8 pesquisadores, sendo 3 estudantes do curso de Letras, 3 alunas do curso de Pedagogia, 1 mestranda em Educação da própria Instituição e a orientadora. Todos os estudantes de graduação possuíam alguma modalidade de bolsa dentre as oferecidas pela UERJ: Estágio Interno Complementar, Extensão, Iniciação Científica, Iniciação à Docência.

Ainda pensando em nosso grupo de pesquisa, interessante é analisar sua composição no contexto de grupos de pesquisa no Brasil. Para isso, podemos nos valer do site do $\mathrm{CNPQ}^{7}$. Nele, encontramos dados variados sobre diretório dos grupos de pesquisa referentes a todas as regiões do Brasil. As informações resultam de censos realizados por este órgão desde 2000.

As informações que encontramos neste site podem nos ajudar a compreender a formação e a produção científica dos grupos de pesquisa no Brasil, consequentemente no Rio de Janeiro e mesmo na UERJ, universidade na qual se vincula o grupo de pesquisa do qual participamos.

Um dado que consideramos interessante se refere ao percentual de grupos de pesquisa por região. A região sudeste possui uma clara hegemonia quando pensamos na quantidade de grupos.

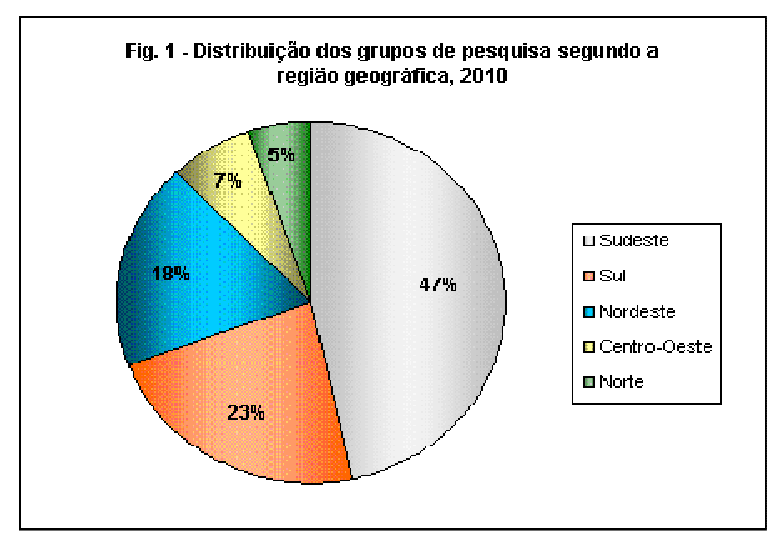

Figura 3: Tabela dos grupos de pesquisa por região

Levando em conta a localização geográfica, podemos ver no mapa acima que na região Sudeste encontramos um acúmulo de $47 \%$ dos grupos de pesquisa, seguida da região Sul com $23 \%$, região Nordeste com $18 \%$, Centro Oeste com $7 \%$ e por fim a região Norte contabilizando $5 \%$ dos grupos de pesquisa.

Por outro lado, quando analisamos a quantidade de grupos por estado, São Paulo e Rio de Janeiro lideram o censo.

Distribuição dos grupos de pesquisa segundo a Unidade da Federação, 2010.

\begin{tabular}{lccc} 
Unidade da Federação & Grupos & \% & \% acumulado \\
\hline São Paulo & 6.359 & 23,1 & 23,1 \\
Rio de Janeiro & 3.313 & 12,0 & 35,1 \\
Minas Gerais & 2.848 & 10,3 & 45,5 \\
Rio Grande do Sul & 2.677 & 9,7 & 55,2
\end{tabular}

Figura 4: Tabela dos grupos de pesquisa por Unidade da Federação

Outro aspecto, que não podemos deixar de mencionar, se refere aos dados relativos à quantidade de grupos de pesquisa por instituição.

\footnotetext{
${ }^{7}$ http://www.cnpq.br/web/guest/pesquisadores
} 
Distribuição dos grupos de pesquisa, pesquisadores e doutores segundo a instituição 2010. ${ }^{1 /}$

\begin{tabular}{|c|c|c|c|c|c|c|c|}
\hline & |lnstituição & Grupos & $\%$ & |Pesquisadores ${ }^{2 /}$ & $\%$ & Doutores $^{2 /}$ & $\%$ \\
\hline 1 & USP & 1.866 & 6,8 & 10.993 & 6,9 & 9.108 & 8,3 \\
\hline 2 & UNESP & 915 & 3,3 & 5.247 & 3,3 & 4.560 & 4,2 \\
\hline 3 & UFRJ & 929 & 3,4 & 4.874 & 3,1 & 4.071 & 3,7 \\
\hline 4 & UNICAMP & 734 & 2,7 & 4.173 & 2,6 & 3.703 & 3,4 \\
\hline 5 & UFMG & 752 & 2,7 & 4.407 & 2,8 & 3.470 & 3,2 \\
\hline 6 & UFRGS & 701 & 2,5 & 4.040 & 2,5 & 3.198 & 2,9 \\
\hline 7 & UFSC & 514 & 1,9 & 2.954 & 1,8 & 2.306 & 2,1 \\
\hline 8 & Embrapa & 251 & 0,9 & 2.845 & 1,8 & 2.299 & 2,1 \\
\hline 9 & UFF & 546 & 2,0 & 2.935 & 1,8 & 2.215 & 2,0 \\
\hline 10 & UFPE & 523 & 1,9 & 2.886 & 1,8 & 2.212 & 2,0 \\
\hline 11 & UFPR & 423 & 1,5 & 2.722 & 1,7 & 2.156 & 2,0 \\
\hline 12 & UNB & 422 & 1,5 & 2.898 & 1,8 & 2.090 & 1,9 \\
\hline 13 & UFBA & 484 & 1,8 & 3.016 & 1,9 & 1.964 & 1,8 \\
\hline 14 & UERJ & 346 & 1,3 & 2.338 & 1,5 & 1.826 & 1,7 \\
\hline
\end{tabular}

Figura 5: Tabela dos grupos de pesquisa por instituição

Pela tabela acima, podemos perceber as posições que as universidades da região sudeste estão ocupando no ranking de distribuição de grupos de pesquisa. A universidade de São Paulo se encontra em primeiro lugar, apresentando um número de 1.866 grupos de pesquisa, com 10.993 pesquisadores. Em seguida, temos a UNESP, com 915 grupos e 5.247 pesquisadores. Logo depois, encontramos a UFRJ, com 929 grupos e 4.874 pesquisadores e a UFF com 546 grupos e 2.935 pesquisadores.

Em relação à UERJ, dados contidos na página da sub-reitoria de Pós- graduação e Pesquisa ${ }^{8}$ da UERJ, e confirmados na tabela acima, produzida pelo CNPQ, nos dão a dimensão dos grupos de Pesquisa em nossa Universidade. Em 2010, a UERJ ocupava a $14^{\circ}$ posição do ranking. Foram contabilizados ao todo 346 grupos de pesquisa na UERJ, compostos por 2.338 pesquisadores, dentre eles 1.826 doutores.

8 Para maiores informações, acessar o site http://www.sr2.uerj.br/
Destes 346 grupos de pesquisa situados na UERJ, a maior parte pode ser encontrada na área de Ciências Humanas, como consta na tabela abaixo.

346 grupos de pesquisa da UERJ distribuídos por áreas de conhecimento:

\begin{tabular}{|l|c|}
\hline ÁREAS & No DE GRUPOS \\
\hline Ciências Agrárias & 01 \\
\hline Ciências Biológicas & 35 \\
\hline Ciências da Saúde & 47 \\
\hline Ciências Exatas e da Terra & 43 \\
\hline Ciências Humanas & 109 \\
\hline Ciências Sociais Aplicadas & 42 \\
\hline Engenharias & 40 \\
\hline Linguística, Letras e Artes & 28 \\
\hline Tecnologias & 01 \\
\hline \hline $\begin{array}{l}\text { Figura 6: Tabela dos grupos de pesquisa na } \\
\text { UERJ }\end{array}$ \\
\hline
\end{tabular}


A tabela acima aponta que o número de pesquisadores na área de Ciências Humanas é superior ao das outras áreas de conhecimento. Inserido neste número está o grupo de pesquisa Vozes da Educação, do qual traremos informações a partir de agora.

O grupo de pesquisa Vozes da Educação, inserido na Faculdade de Formação de Professores da UERJ, se constituiu como um dos principais espaços de formação da estudante que busca se constituir como pesquisadora e que vê num grupo de pesquisa a possibilidade de compartilhar narrativas e saberes. Assim, entendemos como Morais (2008) que o espaço de compartiIhamento com o outro: "possibilita um constante processo de (auto) formação, pois, contar a um outro possibilita (com)partilhar a ação, tornando a experiência infinita ao contrário da vivência que carrega consigo a finitude." ( p.6)

Neste processo de formação, o ambiente da pesquisa se constituiu como fundamental para o desenvolvimento e ampliação da criticidade. 0 pensar/pesquisar/estudar de maneira constante é algo necessário para vida do estudantepesquisador e possível quando este está inserido em um grupo de pesquisa.

\section{ESPAÇOS CULTURAIS: ESPAÇOS DE FORMAÇÃO}

Em nossos encontros de pesquisa, compartilhamos informações sobre eventos culturais como peças de teatro, shows e exposições, sobre livros lançados e sobre aqueles que estamos lendo, além de compartilhamos a respeito de filmes que estão em cartaz e sobre aqueles que assistimos e recomendamos.

$$
\begin{aligned}
& \text { Defendemos a ideia de que a nossa } \\
& \text { formação contínua como bolsis- } \\
& \text { tas/pesquisadores e futuros professores não }
\end{aligned}
$$

consiste somente em praticar leitura e discutir a respeito de textos, mas também pelo acesso a bens culturais. Entendemos que, à medida em que nós transitamos por diversos ambientes culturais, além de ampliarmor nossa visão de mundo, poderemos também desenvolver em sala de aula, com os futuros alunos, os vários conhecimentos adquiridos nestes espaços. Alves e Garcia (2002) afirmam que os docentes que não circulam por espaços culturais:

\begin{abstract}
Dificilmente, farão uma proposta, frente a alunos/alunas que nunca foram ao teatro ou que só vêm filme na televisão, de levá-los a espaços mais amplos de educação, buscando formar redes com conhecimentos desenvolvidos em sala de aula. (p.110)
\end{abstract}

O acesso a expressões da cultura permite que estudantes, bem como professores e professoras, formem redes, como nos falam as autoras acima. Ao transitar por diferentes espaços de formação, estes criam possibilidades de criar propostas de visitação a espaços culturais com seus alunos, especialmente quando estes não têm acesso.

A inserção de um estudante em um grupo de pesquisa pode permitir a este conhecer outros bolsistas/pesquisadores pertencentes a outras instituições universitárias. Esses novos sujeitos podem contribuir para a ampliação da compreensão do que seja cidade e dos lugares a que podemos ter acesso como: teatro, cinema, museus e outros espaços culturais. Podemos, como ensina Vigotsky (1984), ser ajudados a ver e a fazer o que sozinhos ainda não conseguimos. Isto é o que este autor chama de zona de desenvolvimento proximal. 


\section{Cada encontro um acontecimento}

Em cada encontro de nosso grupo de pesquisa vivemos um acontecimento e deste acontecimento, surge um registro escrito. Este importante movimento consiste no exercício de um bolsista, a cada vez, viver a escrita como espaço de reflexão do vivido na reunião. Para isso, deve escrever um texto reflexivo que será lido e comentado por todos do grupo na reunião seguinte. Somos convidados a produzir registros que superem a mera descrição dos acontecimentos vividos naquele dia, mas que se convertam em textos pessoais reflexivos.

Este texto será lido pelo autor na semana seguinte, ganhando vida à medida em que meditamos, criticamos e nos deliciamos com a sua leitura. Nos identificamos com a análise de Kramer sobre os primeiros momentos dos encontros da pesquisa que ela coordenava, momento em que se dava a leitura do registro feito por um membro do seu grupo:

Aqueles dez a quinze minutos tornam-se assim tempo de um para os outros, de todos em um; tempo de trançar laços de coletividade e traçar desse modo a história coletiva que fica registrada, escrita para ser depois lida, pensada, criticada, nunca mudada no âmbito daquela ata, mas reescrita e ressignificada nas seguintes. (KRAMER, 1998, p. 17)

Como no grupo de Kramer, ressignificamos o escrito produzido por um dos membros do grupo. Realizamos uma discussão tanto sobre a forma, quanto sobre o conteúdo do texto, na busca por ampliar olhares. $O$ registro de cada encontro traz os atravessamentos vividos pelo autor do texto e pelos membro do grupo. As impressões, os incômodos e questionamentos se fazem presente no texto, de acordo com a subjeti- vidade de cada autor.

A escrita nos revela, ela não é neutra, mesmo que por vezes tentemos nos esconder. A escrita, muitas vezes, nos entrega. Mais uma vez Kramer nos ajuda a pensar, quando afirma que a escrita é uma: "forma de treinar o pesquisador, que estaria ao mesmo tempo dentro e fora da situação vivida, acompanhando as discussões e sendo capaz de registrá-las por escrito, transcrevendo seus apontamentos." (KRAMER, 1998, p. 17)

Desta forma, acreditamos que a construção do registro é de suma importância para o exercício da escrita, pois contribuí para o aprimoramento e para reflexões acerca do que foi registrado.

Como exemplo, trazemos abaixo um fragmento do registro produzido por uma das bolsistas.

\begin{abstract}
O grupo aumentou, agora são mais pesquisadores para compartilhar as surpresas e progressos do nosso projeto. Recebemos avisos importantes. Um deles foi sobre a atualização do Currículo Lattes. Esse me chamou a atenção. Eu não sabia que era tão importante para a nossa vida acadêmica. (Registro do dia 08/11 2012, escrito por Joseli Damas e lido no dia $14 / 11 / 2012$ )
\end{abstract}

Joseli, em seu, registro utiliza a palavra pesquisadores para se referir aos novos bolsistas, alunos de diferentes cursos de graduação que entravam naquele dia em nosso grupo de pesquisa. O uso da palavra pesquisadores nos possibilita pensar que no espaço do grupo de pesquisa conseguimos superar a ideia de sermos apenas bolsistas para nos afirmarmos como pesquisadores.

Trazemos ainda outro fragmento de registro, desta vez de Naila, feito sobre a reunião do dia 02 de agosto de 2012: 
Durante a leitura do relato, levantamos alguns aspectos importantes para produção de um texto. Um destes aspectos é que: Um texto deve ser escrito de forma que possa ser compreendido pelo leitor. Para isso, devemos buscar formas de melhorá-lo e/ou deixa-lo mais claro. Destacamos também, a questão de não existir o texto certo ou errado, e sim o inadequado. Pude perceber o quanto nossas reuniões são importantes para discutirmos formas que possam aprimorar e exercitar a construção de uma escrita mais compreensível. (Registro do dia 02/08/2012, escrito por Naila Portugal, lido no dia 09/08/2012)

Como produzir um texto compreensível? Como perder o medo da escrita? Estas foram algumas das reflexões que aprofundamos, após a leitura deste registro. Assim, reafirmamos a importância da escrita em nossas reuniões e no percurso de pesquisadores e estudantes.

$\mathrm{O}$ que fomos percebendo, ao longo de nossa experiência, é que a vivência dos bolsistas, nos diferentes espaços de formação, pode exercer uma importante contribuição para a formação do aluno-pesquisador.

\section{FINALIZANDO NOSSAS REFLEXÕES}

Não nasci para ser um professor assim (como sou).

Vim me tornando desta forma no corpo das tramas, na reflexão sobre a ação, na observação atenta a outras práticas, na leitura persistente e crítica. Ninguém nasce feito. Vamos nos fazendo aos poucos, na prática social de que tomamos parte.
(Paulo Freire)

A fala de Freire é um convite à compreensão de quem somos e de quem podemos ser. "Ninguém nasce feito.", diz o autor. Estamos num processo de vir a ser. Sempre em movimento. Sempre em construção e reconstrução.

Muitos são os estudantes que vivem a universidade como espaço apenas de certificação profissional. Mas há também docentes que creem nesta perspectiva. Assim, perdem, estudantes e docentes, a oportunidade de viverem a universidade como espaço mais amplo de formação.

Não é sem razão que encontramos na obra de Freire constantes críticas ao que ele chama de educação bancária. Para que nossos alunos sejam, como nos aponta mais uma vez Freire (1997, p. 51): Capazes de intervir no mundo, de comparar, de ajuizar, de decidir, de romper, de escolher, capazes de grandes ações, de dignificantes testemunhos, não podemos restringir a formação discente como vinculada apenas ao conhecimento disciplinar. E um dos espaços que tem representado ampliação dos modos de ver, entender e intervir no seu próprio mundo, tem sido a participação dos estudantes em grupos de pesquisa. Nossa experiência tem mostrado que viver a universidade, em toda a sua potencialidade, representa um estar diferenciado nesta instituição de ensino e permite aprofundar e ampliar as possibilidades da própria vida, tanto acadêmica como pessoal.

\section{REFERÊNCIAS BIBLIOGRÁFICAS:}

ALVES, N.; GARCIA, R.L. "Conversa sobre pesquisa". In: Professora-pesquisadora: uma práxis em construção. Rio de Janeiro: DP\&A, 2002. 
BRASIL, Lei de Diretrizes e Bases da educação Nacional - LDB - Lei No 9394/96.

\section{$5540 / 68$}

Reforma Universitária. Lei No

FREIRE, Paulo. A importância do ato de ler: em três artigos que se completam. São Paulo: Cortez, 2011.

Pedagogia da autonomia: saberes necessários à prática educativa. São

Paulo: Paz e Terra, 1997.

. Pedagogia da esperança:

um reencontro com a Pedagogia do Oprimido. $22^{\mathrm{a} e d .}$ Rio de Janeiro: Paz e Terra, 1993.

FRISON, L.M.B.; MORAES, M.A.C. "As Práticas de Monitoria como Possibilitadoras dos Processos de Autorregulação das Aprendizagens Discentes".In: Poíesis Pedagógica v.8, n.2 ago/dez.2010; pp.144-158.

KRAMER, Sonia. "Leitura e escrita de professores: da prática de pesquisa à prática de formação". In: Revista Brasileira de Educação. $n^{\circ} 7$, p.17, jan-abr., local, ANPED.

LARROSA, Jorge. "Notas sobre a experiência e o saber de experiência". In: Revista Brasileira de Educação. 2002, no19.

MORAIS, Jacqueline de Fátima dos Santos. "Formação Continuada na Educação Básica: Uma Experiência Compartilhada". In: II Colóquio Práticas de Ensino e Formação de Professores - Práticas em Formação: Tecendo Experiências e Saberes. Rio de Janeiro: UERJ, 2008, CD-ROM.

"Histórias e narrativas

na educação infantil". In: Regina Leite Garcia. (Org.). Crianças, essas conhecidas tão desconhecidas. 1ed.RJ: DP\&A, 2002, v. , p. $81-102$.
Sanches. "Superação da Dicotomia alfabetização e letramento na articulação práticateoria-prática". In: Alfabetização e Letramento: o que muda quando muda o nome. Rio de Janeiro: Rovelle, 2011.

SOUZA, Luciana Karine. Caderno de Pesquisa Interdisciplinar em Ciências Humanas. Florianópolis, v.12, n.101, p.219236, ago/dez 2011.

VYGOTSKY, L. S. A Formação Social da Mente. São Paulo: Martins Fontes, 1984. 